OPEN ACCESS

Edited by:

Aiming Wang,

Agriculture and Agri-Food Canada,

Canada

Reviewed by:

Baozhong Meng,

University of Guelph, Canada

Jesús Navas-Castillo,

IHSM La Mayora, Spain

${ }^{*}$ Correspondence:

Ching-Hsiu Tsa

chtsai1@dragon.nchu.edu.tw

Specialty section:

This article was submitted to

Virology,

a section of the journal

Frontiers in Plant Science

Received: 31 July 2017 Accepted: 22 September 2017 Published: 06 October 2017

Citation:

Chen I-H, Huang Y-P, Tseng C-H,

Ni J-T, Tsai C-H, Hsu Y-H and

Tsai C-H (2017) Nicotiana

benthamiana Elicitor-Inducible

Leucine-Rich Repeat Receptor-Like

Protein Assists Bamboo Mosaic Virus

Cell-to-Cell Movement.

Front. Plant Sci. 8:1736.

doi: 10.3389/fpls.2017.01736

\section{Nicotiana benthamiana Elicitor-Inducible Leucine-Rich Repeat Receptor-Like Protein Assists Bamboo Mosaic Virus Cell-to-Cell Movement}

\author{
I.-Hsuan Chen, Ying-Ping Huang, Ching-Han Tseng, Jian-Tang Ni, Chung-Han Tsai, \\ Yau-Heiu Hsu and Ching-Hsiu Tsai*
}

Graduate Institute of Biotechnology, National Chung Hsing University, Taichung, Taiwan

For successful infection, a virus requires various host factors at different stages such as translation, targeting, replication, and spreading. One of the host genes upregulated after Nicotiana benthamiana infection with Bamboo mosaic virus (BaMV), a singlestranded positive-sense RNA potexvirus, assists in viral movement. To understand how this host protein is involved in BaMV movement, we cloned its full-length cDNA by rapid amplification of cDNA ends. The gene has $3199 \mathrm{nt}$ and encodes a 969-amino acid polypeptide. The sequence of the encoded polypeptide is orthologous to that of $N$. tabacum elicitor-inducible leucine-rich repeat (LRR) receptor-like protein (NtEILP), a plant viral resistance gene, and is designated NbEILP. To reveal how NbEILP is involved in BaMV movement, we fused green fluorescent protein (GFP) to its C-terminus. Unfortunately, the gene's expression in $N$. benthamiana was beyond our detection limit possibly because of its large size $(\sim 135 \mathrm{kDa})$. However, NbEILP at such low expression could still enhance BaMV accumulation in inoculated leaves. A short version of NbEILP was constructed to remove the LRR domain, NbEILP/ALRR-GFP; the expression of this deletion mutant could still enhance BaMV accumulation to 1.7-fold that of the control. Hence, the LRR domain in NbEILP is not an essential element in BaMV movement. We constructed a few deletion mutants - NbEILP/ $\Delta$ LRR $\Delta T M D$ (without the transmembrane domain), NbEILP/ $\Delta \mathrm{LRR} \Delta \mathrm{CD}$ (without the cytoplasmic domain), and $\mathrm{NbEILP} / \Delta \mathrm{LRR} \Delta \mathrm{SP}$ (without the signal peptide) - to examine whether these domains are involved in BaMV movement. For BaMV movement, NbEILP requires the signal peptide to target the endoplasmic reticulum and the transmembrane domain to retain on the membrane.

Keywords: EILP, ER-targeting, viral movement, BaMV, Nicotiana benthamiana

\section{INTRODUCTION}

Bamboo mosaic virus (BaMV) has a flexuous rod-shaped particle (Lin et al., 1977; DiMaio et al., 2015). The genome of BaMV is a single-strand positive-sense RNA of $\sim 6.4 \mathrm{~kb}$ [excluding the $3^{\prime}$ poly(A) tail] and belongs to the Potexvirus genus of the family Alphaflexiviridae (Lin et al., 1994). The RNA genome comprises the $5^{\prime}$-end 7 methyl-guanosine cap, the $5^{\prime}$ untranslated region (UTR), 
five open reading frames (ORFs), the $3^{\prime}$ UTR, and a $3^{\prime}$ end of approximately 300 adenylates (Lin et al., 1994; Chen et al., 2005). ORF1 encodes a $155-\mathrm{kDa}$ replicase for viral RNA capping and replication ( $\mathrm{Li}$ et al., 1998, 2001a,b; Huang et al., 2005; Meng and Lee, 2017). ORFs 2-4 overlap, called triple gene block (TGB), and encode movement-related polypeptides, with 28,13 , and $6 \mathrm{kDa}$ designated as TGBp1, -2 , and -3 , respectively (Lin et al., 2004, 2006). ORF5 encodes a $25-\mathrm{kDa}$ coat protein (CP) for viral encapsidation, movement, and symptom determination (Lan et al., 2010; Lee et al., 2011; DiMaio et al., 2015). The 3' UTR of BaMV interacts with viral-encoded replicase and has roles in minus-strand RNA synthesis, polyadenylation, and long-distance movement (Chen et al., 2017).

The spread of plant viruses from the infected cell can be classified into two modes: the short-distance cell-to-cell movement is via plasmodesmata (PD) with the assistance of virus-encoded movement proteins and host factors (Chou et al., 2013), and the long-distance systemic movement being via vascular tissue (Ryabov et al., 1999). The cell-to-cell movement can be tubule-guided, such as with Cauliflower mosaic virus, which encodes movement protein to form tubules and directs the virion particles to pass through (Perbal et al., 1993), or non-tubule-guided, such as with Tobacco mosaic virus, which encodes movement protein (p30) to increase the plasmodesmal size exclusion limit (SEL) and facilitates viral movement (Wolf et al., 1989). In potexviruses such as Potato virus $X$, TGBp1 is involved in RNA binding, ATPase, helicase activities, increasing the plasmodesmal SEL (Howard et al., 2004), and formatting the $\mathrm{PD}$-transportable ribonucleic protein movement complex. TGBp2 with two transmembrane domains and TGBp3 with one domain are endoplasmic reticulum (ER)-associated proteins (Krishnamurthy et al., 2003; Mitra et al., 2003). TGBp2 and TGBp3 together with CP and TGBp1 form a complex on the ER membrane (Park et al., 2014). The C-terminal tail of BaMV TGBp2 could direct the TGBp1 to localize at the PD (Ho et al., 2017). Furthermore, the active replicase complex with viral RNA is associated with the movement complex (Chou et al., 2013).

The coding capacity of a small viral RNA genome is limited to facilitate the infection and replication cycle; the RNA virus requires different host proteins directly or indirectly to assist its accumulation (Ahlquist et al., 2003; Hyodo and Okuno, 2016; Nagy, 2016). A few host proteins associated with viral RNA or the RdRp complex are involved in BaMV replication such as the chloroplast phosphoglycerate kinase, heat-shock protein 90, and glutathione S-transferase U4 (Huang et al., 2017). The host proteins RabGTPase-activating protein 1, serine/threonine kinase-like protein, and casein kinase $2 \alpha$ participate in BaMV movement (Huang et al., 2017).

A group of proteins with a leucine-rich repeat (LRR) motif from tobacco responding to fungal elicitors and playing a role in defense were designated elicitor-inducible LRR receptorlike proteins (EILPs). Similar proteins in tomato called $C f$ proteins confer resistance to the fungus Cladosporium fulvum by recognizing its avirulence proteins secreted during infection (de Wit and Joosten, 1999; Joosten and de Wit, 1999; Dixon et al., 2000; Dangl and Jones, 2001). The basal expression of EILP is low and is increased by treatment with elicitors, which implies that EILP is involved in both preexisting and inducible surveillance systems (Takemoto et al., 2000).

We cloned the full-length cDNA of an EILP involved in BaMV movement in Nicotiana benthamiana and designated it NbEILP. We also characterized how NbEILP is involved in BaMV movement.

\section{MATERIALS AND METHODS}

\section{Plasmid Construction and Gene Expression Knockdown}

The plasmids pTRV1 and pTRV2 were used for Tobacco rattle virus (TRV)-based virus-induced gene silencing (VIGS) to knock down host gene expression (Ruiz et al., 1998). The primer set ACCT8-1-5'/KD (5'-CGAACTCCCAACTG GCTTTCTTGG-3') and ACCT8-1-3'/KD (5'-TAACTCCTCC AGAAGCAAATAGTTTC-3') was used for PCR amplification of the fragment (Figure 1) identified from cDNA-amplified fragment length polymorphism (cDNA-AFLP) (Cheng et al., 2010). The cDNA fragment was cloned into pGEM-T Easy vector (Promega, Madison, WI, United States) and then subcloned into pTRV2 with the EcoRI site. The resulting plasmid pTRV2/NbEILP was used to knock down NbEILP expression. The negative and positive controls were pTRV2/Luc containing a 398-bp sequence derived from the Luciferase gene and pTRV2/PDS containing the phytoene desaturase (PDS) sequence, respectively.

Agrobacteria containing pTRV1 or various pTRV2 constructs were cultured in $1 \mathrm{~mL} 2 \mathrm{YT}$ broth at $30^{\circ} \mathrm{C}$ overnight, then transferred to $10 \mathrm{~mL} 2 \mathrm{YT}$ broth for growth to $\mathrm{OD}_{600}=0.8 \sim 1.5$. After centrifugation at $5000 \times g$ for $10 \mathrm{~min}$, cells were resuspended in induction buffer $\left(10 \mathrm{mM} \mathrm{MgCl}_{2}, 10 \mathrm{mM}\right.$ MES pH 5.7, and $200 \mu \mathrm{M}$ acetosyringone). pTRV1 was mixed with each TRV2 construct in a 1:1 ratio, then infiltrated onto the second, third, and fourth leaves above the cotyledon of 1-month-old $N$. benthamiana plants.

\section{Cloning the Full-Length NbEILP cDNA}

To clone the full-length cDNA of NbEILP, $3^{\prime}$ rapid amplification of cDNA ends (RACE) was used to extend the downstream sequence containing the poly $(\mathrm{A})$ tail of the $\mathrm{CDNA}$ derived from cDNA-AFLP. A degenerate primer XhoI-KpnI-SmaI-25T-NN (5'-GCTCGAGGTACCCGGGT ${ }_{25} \mathrm{NN}-3^{\prime}$; N: G, A, T, or C) was used for reverse transcription. The specific cDNA fragment PCR-amplified with the primer set ACCT8-1-5'/KD and XhoIKpnI-SmaI (5'-GCTCGAGGTACCCGGG-3') was cloned and sequenced. The forward primer ACCT8-1/elongation_F (5'-GA ACTTGTTAGAATTTTGACAGTTTACAC- $\left.3^{\prime}\right)$ and reverse primer ACCT8-1/5'RACE_R (5'-TATGACAGACATGTCATAA AATAGGGCTG-3') and a nested reverse primer ACCT8-1/ 5'RACEupR (5'-CGCCAACATCAACAAATCATTGACATCTG$\left.3^{\prime}\right)$ were used to extend the fragment to $849 \mathrm{bp}$. For the final step of $5^{\prime}$ RACE, reverse primers ACCT8-1/5'RACE2-2 (5'GAGTGAGGGTGGTATGCGACCTTGCAAC-3') and ACCT8 
-1/5'RACE2-n2 (5'-CGTGTAAACTGTCAAAATTCTAACAA GTTC-3') were used with the SMARTer RACE CDNA Amplification Kit (Clontech) to extend the sequence toward the $5^{\prime}$ end of the gene.

\section{Western Blot Analysis}

Total protein extracted from plants or protoplasts was separated on $12 \%$ polyacrylamide gels containing $0.1 \%$ SDS (SDS-PAGE). After separation, the upper portion of the gel containing proteins $>40 \mathrm{kDa}$ including $\mathrm{rbcL}$ (RuBisCO large subunit used as a loading control) was stained with Coomassie blue $(0.1 \%$ w/v Coomassie Brilliant Blue R-250, 50\% methanol, 10\% acetic acid) and destained with destaining buffer (10\% acetic acid, $30 \%$ methanol). The stained gel was scanned and quantified by using LI-COR Odyssey. The lower portion of gel containing proteins $<40 \mathrm{kDa}$ including the $\mathrm{BaMV} \mathrm{CP}$ was transferred onto a nitrocellulose membrane (PROTRAN BA 85 Schleicher and Schnell), which was incubated with rabbit anti-BaMV $\mathrm{CP}$ antibody at $4^{\circ} \mathrm{C}$ for overnight then with anti-rabbit IgGconjugated IRDye 800 secondary antibody at room temperature for $1 \mathrm{~h}$ (Rockland Immunochemicals, Gilbertsville, PA, United States).

For the detection of transiently expressed NbEILP-GFP and its derivatives, the membrane was incubated with the antiGFP primary antibody, then with the horseradish peroxidase (HRP)-conjugated secondary antibody. The HRP signal (Sensido Advance ECL Substrate kit; Recenttec Inc., Taiwan) was detected by FUJIFILM Image Reader LAS-4000 (Fujifilm Holdings Corp., Japan).

\section{Northern Blot Analysis}

Total RNA harvested from inoculated leaves was denatured in glyoxal buffer (50\% DMSO, $1 \mathrm{M}$ glyoxal, $10 \mathrm{mM}$ sodium phosphate buffer) for $1 \mathrm{~h}$ at $50^{\circ} \mathrm{C}$, separated in $1 \%$ agarose gel, and transferred onto Zeta-probe nylon membranes (Bio-Rad Laboratories, Taiwan), which were incubated in $0.2 \mathrm{~N} \mathrm{NaOH}$ buffer for $30 \mathrm{~min}$ (Tsai and Dreher, 1991) and prehybridized with $1 \times$ SET buffer $(150 \mathrm{mM} \mathrm{NaCl}, 2 \mathrm{mM}$ EDTA, $30 \mathrm{mM}$ Tris$\mathrm{HCl}$ pH 8.0$), 0.1 \%$ sodium phosphate, $0.6 \%$ SDS, $10 \times$ Denhardt's (2\% Ficoll, $2 \%$ polyvinylpyrrolidone, $2 \%$ bovine serum albumin), $10 \mathrm{mg} / \mathrm{ml}$ salmon sperm DNA, $0.25 \mathrm{mg} / \mathrm{ml}$ yeast RNAs for $4 \mathrm{~h}$ at $65^{\circ} \mathrm{C}$. The probe, the $3^{\prime}$-end 0.6-kb BaMV RNA (Lin et al., 1994), was in vitro-transcribed from the linear plasmid pBaMVO/SB2.6 with $\left[\alpha-{ }^{32}\right.$ P]UTP labeling (Huang and Tsai, 1998) and added into the hybridization buffer (same as the prehybridization buffer). After hybridization, the radioactivity on the membranes was determined by using PhosphoImager (Fujifilm BAS 2500, Tokyo).

\section{Real Time-Quantitative RT-PCR}

Approximately $1 \mu \mathrm{g}$ total RNA was mixed with $1 \mu \mathrm{l} 20$ pmole reverse transcription (RT) primer XhoI-KpnI-SmaI-25T-NN and incubated at $70^{\circ} \mathrm{C}$ for $5 \mathrm{~min}$, then quickly cooled on ice. After mixing, $4 \mu \mathrm{l}$ of $5 \mathrm{x}$ RT buffer, $2.4 \mu \mathrm{l}$ of $25 \mathrm{mM} \mathrm{MgCl}_{2}, 1 \mu \mathrm{l}$ of $10 \mathrm{mM}$ dNTP, $0.3 \mu \mathrm{l}$ RNase inhibitor (Invitrogen, Carlsbad, CA, United States), $1 \mu l$ reverse transcriptase (Promega), and deionized water was added to total $20 \mu$ l. The mixture was incubated at $25^{\circ} \mathrm{C}$ for $5 \mathrm{~min}$, then quickly transferred to $42^{\circ} \mathrm{C}$ for $60 \mathrm{~min}$. Finally, the reaction was stopped by incubating at $70^{\circ} \mathrm{C}$ for $15 \mathrm{~min}$. qPCR was performed in a $20 \mu \mathrm{l}$-reaction containing a 1000X dilution of SYBR green I (Cambrex Bio Science Rockland, Rockland, ME, United States) with $0.6 \mathrm{mM}$ of the primer pair 5'CT18_KD (5'-GAGAAGGCGCAAGAAGC$\left.3^{\prime}\right)$ and $3^{\prime} / \mathrm{CT} 18$ KD (5'-CAAATGTAAACACATATGACAGAC$3^{\prime}$ ) in $0.2-\mathrm{ml}$ PCR tubes. The conditions began with an initial denaturation at $95^{\circ} \mathrm{C}$ for $3 \mathrm{~min}$, followed by 40 cycles of $95^{\circ} \mathrm{C}$ for $3 \mathrm{~s}$ and $60^{\circ} \mathrm{C}$ for $20 \mathrm{~s}$ by use of the KAPA SYBR FAST qPCR Kit (KAPA Biosystems, Boston, MA, United States). Reactions were performed in a TOptical Gradient 96 (Biometra, An Analytik Jena Company, Germany) with data acquisition at $60^{\circ} \mathrm{C}$ on the channel, excitation at $470 \mathrm{~nm}$ and detection at $585 \mathrm{~nm}$. The reaction without template or reverse transcriptase was a negative control, and actin was amplified with the primer set actin_5' (5'-GATGAAGATACTCACAGAAAGA$\left.3^{\prime}\right)$ and actin_3' (5'-GTGGTTTCATGAATGCCAGCA-3') for normalization.

\section{Measurement of BaMV Cell-to-Cell Movement}

About $10 \mu \mathrm{g}$ of the plasmid pCBG (Lin et al., 2004), a BaMV infectious cDNA clone containing the GFP reporter gene and driven by a $35 \mathrm{~S}$ promoter, was mechanically inoculated onto the fourth leaf above the Agrobacterium-infiltrated knockdown leaf of $N$. benthamiana. Green fluorescent lesions on inoculated leaves were observed by fluorescent microscopy (Olympus IX71) at 4 days post-inoculation (dpi). The lesion size was measured by using Image $\mathrm{J}^{1}$.

\section{Construction of NbEILP-Deletion Mutants}

To construct the LRR domain-deletion mutant, the primer pair BsmIACCT8-1/2643F (5'-GAATGCTTTCAAGGACCTCA ATTTGCAAC-3') and KpnI/ ACCT8-1/2986R (5'-GGTACCT CTTCTGTTGTGCCTTTGACAGGCTC-3') (sites for restriction enzymes BsmI and KpnI are underlined) was used to amplify the $3^{\prime}$ portion of NbEILP including the spacer, acidic, transmembrane, and cytoplasmic domains (Figure 1). The amplified DNA fragment was cloned into the pGEM-T Easy vector and sequenced.

To construct the transmembrane domain-deletion mutant, two fragments were PCR-amplified with the primer pair BamHI80F (5'-GGATCCATGATGATGGTTCCCAAATTATCT TCTCTTC-3') and Del_TMD_3' (5'-TCCAAGAAAGCCATTT CCAGAAATCATTGAG- $3^{\prime}$ ) for the $5^{\prime}$ portion and the primer pair Del_TMD_5' (5'-TCTCAATGATTTCTGGAAATGGCTTT CTTGG-3') and KpnI2986R (5'-GGTACCTCTTCTGTTGTG CCTTTGACAGGCTC- $3^{\prime}$ ) for the $3^{\prime}$ portion, with pNbEILP/ $\triangle$ LRR-GFP used as a template. Two PCR fragments were gelpurified and mixed for another round of PCR amplification with the primer pair BamHI80F and KpnI2986R to generate a 483-bp fragment. The PCR product was cloned and sequenced. The resulting mutant was designated NbEILP/ $\triangle$ LRR $\triangle \mathrm{TMD}$.

\footnotetext{
${ }^{1}$ http://rsbweb.nih.gov/ij/
} 


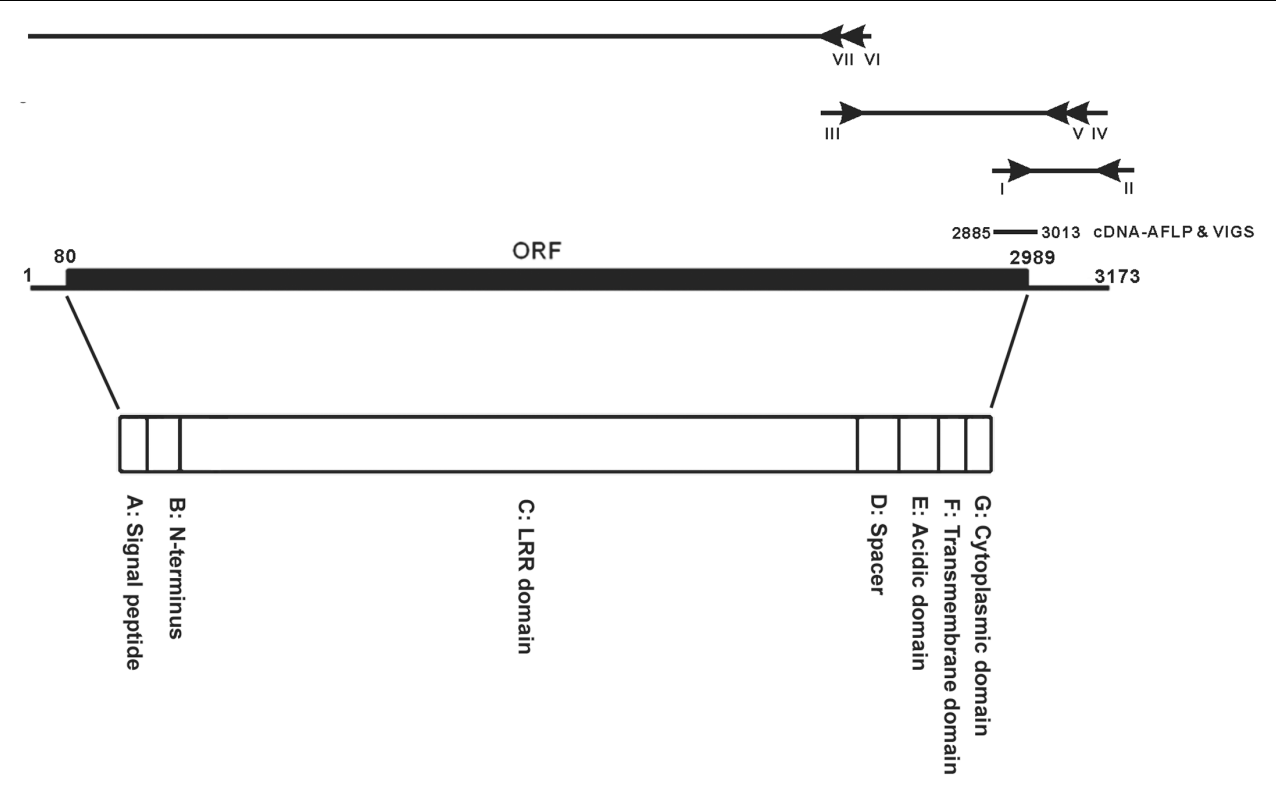

FIGURE 1 | cDNA organization of NbEILP. A diagram to depict the $5^{\prime}$ and $3^{\prime}$ RACE of identifying the sequence of the full-length cDNA of NbEILP was illustrated. The primers used in the experiment were shown as I: ACCT8-1-5'/KD (nt 2885-2908), II: Xhol-Kpnl-Smal, III: ACCT8-1/elongation_F (nt 2351-2379), IV: ACCT8-1/5'RACE_R (nt 3109-3081), V: ACCT8-1/5'RACEupR (nt 3048-3020), VI: ACCT8-1/5'RACE2-2 (nt 2503-2476), and VII: ACCT8-1/5'RACE2-n2 (nt 2380-2351). The open reading frame (ORF; nt 80-2989) and cDNA-AFLP fragment (nt 2885-3013) used for VIGS. The encoded polypeptide is divided into the seven domains $(A-G)$ indicated.

To construct the cytoplasmic domain-deletion and signal peptide-deletion mutants, the plasmid pNbEILP/ $\triangle$ LRR-GFP was used as the template with the primer pairs BamHI80F and KpnI_dCD_3' (5'-GGTACCGTTGGGAGTTCGAGCTGAAAG CATGAAATATG-3') and BamHI_dSP_5' (5'-GGATCCATGAT GATG TCCACAGAGGAAGCAACTG-3') and KpnI2986R, respectively. The PCR fragments were cloned and sequenced. The resulting constructs were designated NbEILP/ $\triangle \mathrm{LRR} \Delta \mathrm{CD}$ and NbEILP/ $\triangle$ LRR $\Delta$ SP. All mutant constructs in T-Easy vector were digested with BamHI and $K p n I$ and sub-cloned into the expression vector pBIN-mGFP1, with GFP fused at the C-terminus.

\section{Virus Inoculation and Transient Expression}

Agrobacteria containing pBIN-NbEILP-mGFP (pBIN61 vector containing NbEILP fused with mGFP), its derivatives (NbEILP mutants) or pBIN-p19 were cultured in $1 \mathrm{~mL} 2 \mathrm{YT}$ broth at $30^{\circ} \mathrm{C}$ overnight, then applied to $10 \mathrm{~mL} 2 \mathrm{YT}$ broth and grown to $\mathrm{OD}_{600}=0.8 \sim 1.5$. After centrifugation at $3500 \mathrm{rpm}$ for $20 \mathrm{~min}$, cells were resuspended in the induction buffer $\left(10 \mathrm{mM} \mathrm{MgCl}_{2}, 0.1\right.$ $\mathrm{M}$ MES pH 5.7, and $750 \mu \mathrm{M}$ acetosyringone). Then the NbEILPdeletion constructs were mixed with the one containing a p19 silencing suppressor at a ratio of 1:1 at final $\mathrm{OD}_{600}=1$.

Nicotiana benthamiana plants were grown in a growth room with temperature kept at $28^{\circ} \mathrm{C}$ and $16-\mathrm{h}$ light $/ 8$-h dark cycle. Leaves from 3-week-old plants were mechanically inoculated with $50 \mathrm{ng}$ BaMV virion per leaf. At $2 \mathrm{dpi}$, inoculated leaves were agro-infiltrated with various constructs to transiently express proteins. At 4 dpi (2 days post-infiltration), approximately $0.1 \mathrm{~g}$ leaf was collected and smashed into powder with liquid nitrogen.

\section{Transient Expression of NbEILP and Protoplast Isolation}

mCherry derived from Discosoma sp. (Shaner et al., 2004) is a monomeric red fluorescent protein with peak absorption at $587 \mathrm{~nm}$ and emission $610 \mathrm{~nm}$. ER-rk, originally used as an ER marker in the CD3-959 cell line (Nelson et al., 2007) and targeting the ER with red fluorescence, was modified to use as a plant ER marker driven by double $35 \mathrm{~S}$ promoters and signal peptide in the pBIN20 binary plasmid. The second or third leaf of 3-week-old $N$. benthamiana plants was agro-infiltrated with NbEILP or its derivatives with $\mathrm{p} 19$ and mCherry in a 1:1:1 ratio.

The preparation of protoplasts from $N$. benthamiana was as described (Tsai et al., 1999). Briefly, approximately $2 \mathrm{~g}$ of leaves with transient expression was used for protoplast isolation. The intact protoplasts were collected from the interphase of sucrose and Mannitol-MES after removing the cell wall. Finally, protoplasts were re-suspended in Mannitol-MES after a few steps of washing and stained with fluorescein diacetate to examine the quality and quantity of cells under a fluorescent microscope.

\section{Cell Extract Fractionation}

Approximately $1 \mathrm{~g}$ infiltrated leaf at 2 days post-infiltration was homogenized with $2 \mathrm{ml}$ extraction buffer $(50 \mathrm{mM}$ Tris- $\mathrm{HCl}$ $\mathrm{pH} 7.6,15 \mathrm{mM} \mathrm{MgCl}$, and $120 \mathrm{mM} \mathrm{KCl}, 20 \%$ glycerol, $0.1 \%$ $\beta$-mercaptoethanol, and the protease inhibitor) and centrifuged at $4^{\circ} \mathrm{C}$ with $400 \times g$ for $10 \mathrm{~min}$ (Laliberte et al., 2007). The supernatant was collected and centrifuged at $4^{\circ} \mathrm{C}$ with $21,300 \times g$ 
A

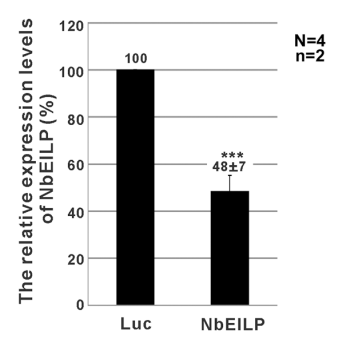

C

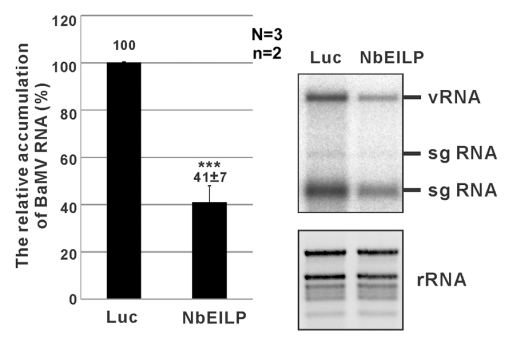

B

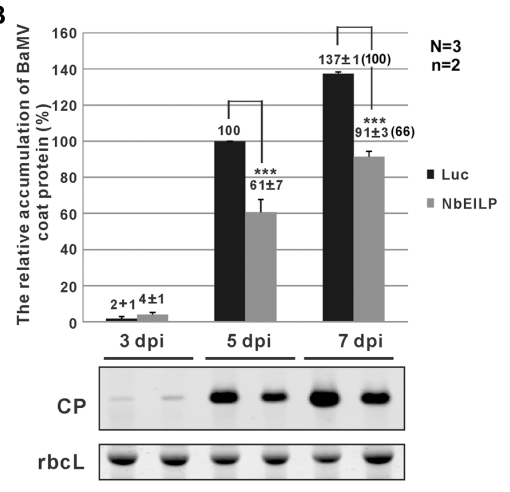

D

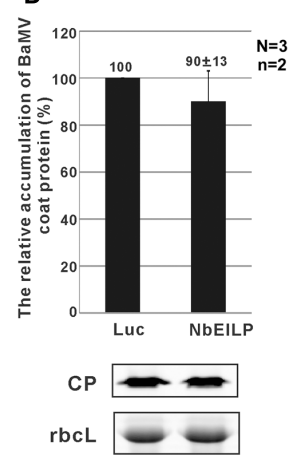

E

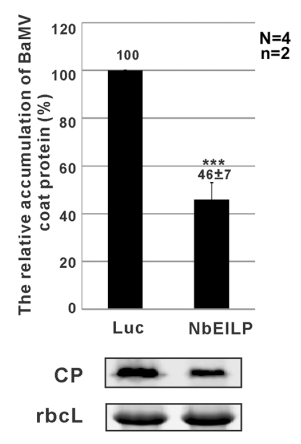

FIGURE 2 | Bamboo mosaic virus (BaMV) accumulation in NbEILP-knockdown plants. (A) The expression level of NbEILP was determined by real-time quantitative RT-PCR in LUC- and NbEILP-knockdown leaves. The numbers above each bar are the mean expression of $N b E I L P$ with the standard error obtained from at least three independent experiments. (B) Western blot analysis of the relative accumulation of BaMV coat protein in Luc- and NbEILP-knockdown leaves at 3, 5, and 7 days post-inoculation (dpi). The accumulation of BaMV coat protein in Luc-knockdown leaves at 5 dpi was set as $100 \%$. The number in the parentheses at 7 dpi is the relative ratio of the accumulation. The representative western blot is shown under the statistical analysis. (C) Northern blot analysis of the relative accumulation of BaMV RNA in LUC- and NbEILP-knockdown leaves in 5 dpi. The accumulation of BaMV genomic RNA in Luc-knockdown leaves was set as 100\%. The representative Northern blot is shown by the statistical analysis. vRNA: viral genomic RNA; sgRNA: viral subgenomic RNA; rRNA: ribosomal RNAs. (D,E) Western blot analysis of the relative accumulation of BaMV coat protein in protoplasts at $24 \mathrm{hpi}$ and systemic leaves at $7 \mathrm{dpi}$ of Luc- and NbEILP-knockdown plants, respectively. The accumulation of BaMV coat protein in Luc-knockdown was set as $100 \%$. The numbers above each bar were the relative mean accumulation of BaMV with the standard error derived from the number of independent experimental repeats $(\mathrm{N})$ and the number of plants ( $\mathrm{n}$ ) used in each repeat. Luc: luciferase-knockdown plants; NbEILP: NbEILP-knockdown plants; CP: coat protein; and rbcL: RuBisCo large subunit used as a loading control. Asterisks indicate statistically significant differences compared with the group indicated $\left({ }^{*} P<0.05,{ }^{* *} P<0.005,{ }^{* * *} p<0.001\right)$ by Student's $t$-test.

for $35 \mathrm{~min}$ to separate the soluble fraction (supernatant) and the membrane fraction (pellet). The membrane fraction was resuspended in $2 \mathrm{ml}$ extraction buffer. Part of the fractions was mixed with $4 \mathrm{X}$ sample buffer (250 mM Tris- $\mathrm{HCl} \mathrm{pH} \mathrm{6.8,} \mathrm{40 \%}$ glycerol, $0.02 \%$ bromophenol blue, and $10 \% \beta$-mercaptoethanol) and boiled for $5 \mathrm{~min}$. The proteins were separated on $12 \%$ SDS-polyacrylamide gel and subjected to western blot analysis.

\section{RESULTS}

\section{A Gene Represented by ACCT8-1 Upregulated after BaMV Inoculation Is an EILP}

A cDNA fragment, ACCT8-1 (129 bp), identified by cDNA-AFLP, was derived from an upregulated gene after BaMV inoculation in $N$. benthamiana and found to participate in BaMV infection
(Cheng et al., 2010). RACE was used to clone the $3^{\prime}$ end of the gene. The $3^{\prime}$-end sequence of the gene was searched in known databases and found similar to a cDNA fragment of a plant resistant gene in N. tabacum, CHO_SL009xg14f1.ab1 CHO_SL. Accordingly; a primer (ACCT8-1/elongation F) was designed to extend the sequence up to $849 \mathrm{bp}$ of the gene from $N$. benthamiana. $5^{\prime}$ RACE with 2 reverse primers (Figure 1) was used to extend the length of the cDNA to the $5^{\prime}$ end of the gene. The full-length gene is $3173 \mathrm{bp}$, with 79 and $184 \mathrm{bp}$ of the $5^{\prime}$ and $3^{\prime}$ UTRs, respectively (Figure 1). The ORF of this full-length cDNA encodes a 969 amino acid polypeptide (Figure 1).

The amino acid sequence is homologous to the EILP gene of N. tabacum (Supplementary Figure S1) and the Cf-2/Cf-5 gene family of tomato (Supplementary Figure S2). ACCT81 protein has the same seven domains (A-G) (Figure 1) as members of the $C f-2 / C f-5$ family (Supplementary Figure S2). Domain $A$ is a 25 -amino acid putative signal peptide for ER entry; domain $\mathrm{B}$ is presumed to be the $\mathrm{NH}_{2}$-terminus of the 
mature ACCT8-1 protein; domain C includes all 32 LRRs, whose structure is very similar to that of $C f-2 / C f-5$ and EILP; domain $\mathrm{D}$ is a spacer with no known function; domain $\mathrm{F}$ is a membrane-spanning region; and domains $\mathrm{E}$ and $\mathrm{G}$ are the acidic domain and the short cytoplasmic portion rich in basic amino acids, respectively (Figure 1). The polypeptide translated in silico is very similar to proteins of the $C f$ gene family in tomato that encode the transmembrane receptor-like proteins with extracellular LRRs and a short (23 to 36 amino acid) cytoplasmic domain. Therefore, we designated this gene NbEILP (GenBank accession no. MF346698).

\section{BaMV Accumulation Is Reduced in $N$. benthamiana with NbEILP Knockdown}

To study the relation between NbEILP and BaMV accumulation in $N$. benthamiana, TRV-based VIGS was used to knock down NbEILP expression before BaMV inoculation. The morphology of NbEILP-knockdown plants and control plants (agroinfiltrated with TRV2/Luc) did not differ (Supplementary Figure S3). Real-time qRT-PCR revealed the expression of $N b E I L P$ reduced to $48 \%$ of the wildtype level in knockdown plants (Figure 2A). BaMV CP level was significantly reduced to approximately 61 and $66 \%$ that of control plants at 5 and 7 dpi (Figure 2B). BaMV genomic RNA level was also reduced to approximately $41 \%$ in knockdown plants at 5 dpi (Figure 2C). However, this effect did not occur on infection with Potato virus $X$ and Cucumber mosaic virus in NbEILP-knockdown plants (Supplementary Figure S4). These results suggest a specific involvement of NbEILP in BaMV accumulation.

\section{NbEILP Is Involved in BaMV Cell-to-Cell Movement}

The reduced BaMV accumulation in NbEILP-knockdown plants could result from an effect on viral RNA replication or cell-to-cell movement. To reveal which effect is the major cause restricting BaMV accumulation in knockdown plants, we prepared protoplasts from knockdown plants whereby the cell wall was removed and plasmodesmata were excluded. The accumulation of BaMV CP did not differ between knockdown and control protoplasts at $24 \mathrm{~h}$ post-inoculation (hpi; Figure 2D). Therefore, reduced expression of NbEILP had no effect on BaMV replication. Hence, NbEILP may be involved in movement of BaMV in plants.

To determine whether NbEILP also plays a role in longdistance movement, we examined BaMV accumulation in upper, non-inoculated leaves. The accumulation of BaMV CP in NbEILP-knockdown plants was reduced to approximately $46 \%$ that of the control plants at 7 dpi (Figure 2E). Because BaMV accumulation was shown no obvious difference in upper noninoculated and inoculated leaves (Figure 2B), NbEILP has less effect on systemic movement but mainly on cell-to-cell movement.

To validate this conclusion, we examined viral movement in NbEILP-knockdown plants. We inoculated knockdown plants

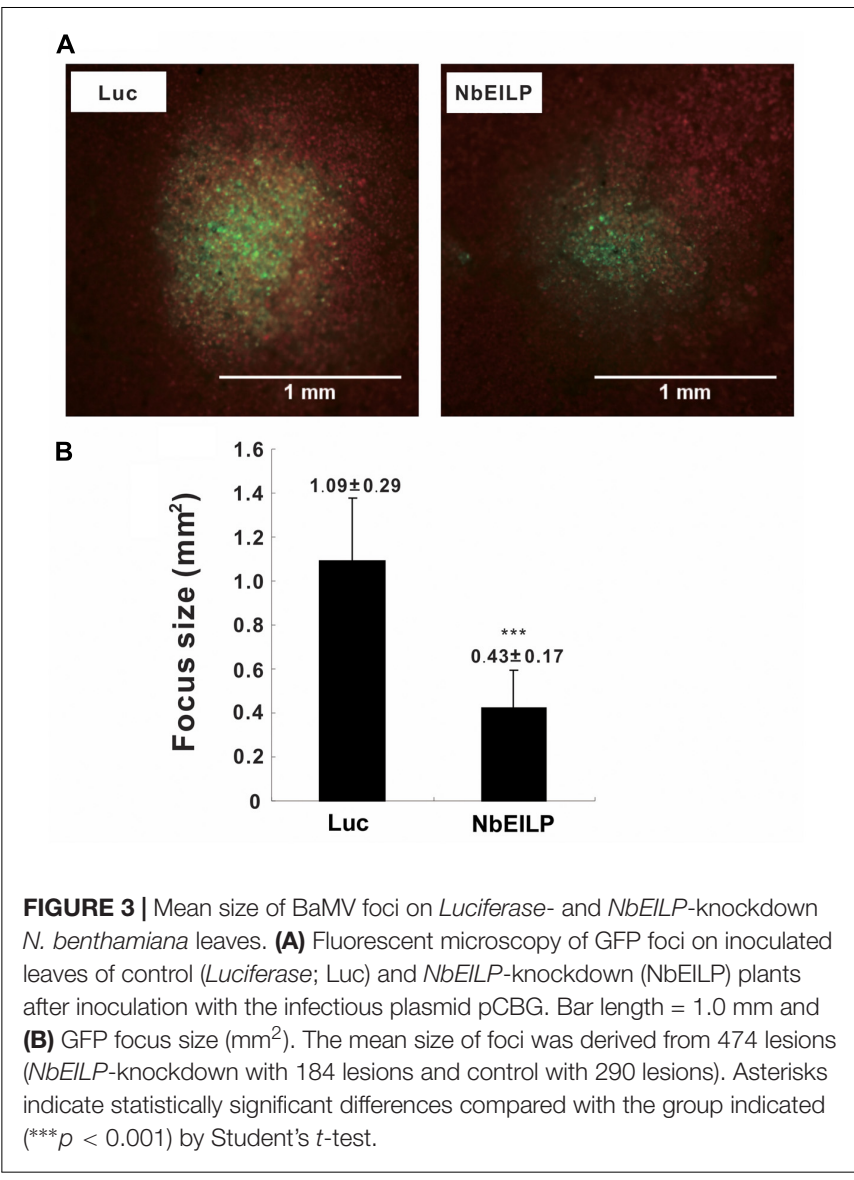

with the infectious cDNA plasmid pCBG (Lin et al., 2004), which carries the GFP reporter gene. The number and size of fluorescent foci were examined by fluorescent microscopy. The mean size of BaMV foci was approximately $0.43 \mathrm{~mm}^{2}$ in NbEILP-knockdown plants and was much smaller than the $1.09 \mathrm{~mm}^{2}$ size in control plants (Figure 3). Hence, the reduced expression of NbEILP restricted BaMV movement in N. benthamiana plants.

\section{NbEILP Is Localized at the ER Membrane}

Because the sequence of NbEILP contains a signal peptide and a transmembrane domain, we would expect NbEILP to be localized at the ER membrane. Therefore, we fused NbEILP and its derivatives with GFP at their C-termini to localize their expression in cells. After transient expression of the full-length NbEILP-GFP, we did not observe any GFP signal in plants. Therefore, we constructed and expressed a short version of NbEILP with deletion of LRR. NbEILP/ $\triangle$ LRR-GFP and the ER marker (mCherry) co-localized in cells on confocal microscopy. This result confirmed that NbEILP/ $\triangle$ LRR is localized at the ER membrane (Figure 4).

\section{Expression of NbEILP and NbEILP/ $\Delta$ LRR Enhance BaMV Accumulation}

The results from knockdown experiments suggested that NbEILP could specifically help with BaMV accumulation. To confirm 


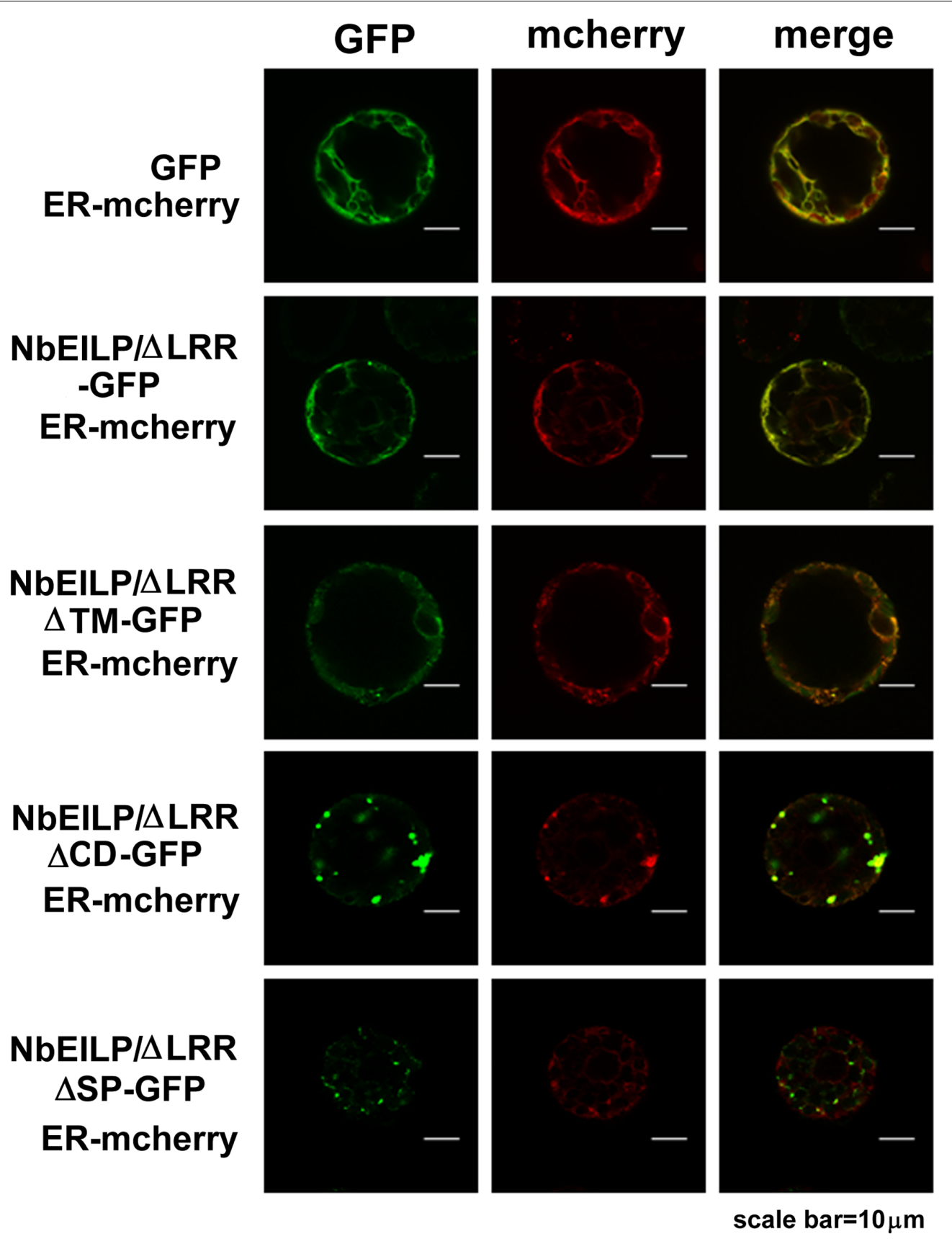

FIGURE 4 | Visualization of NbEILP derivative-GFP and ER-mCherry (ER membrane) constructs in N. benthamiana protoplasts. NbEILP derivative constructs were transiently expressed in $N$. benthamiana leaves by agro-infiltration. Confocal microscopy of protoplasts isolated from inoculated leaves. Scale bar: $10 \mu \mathrm{m}$.

this finding, we transiently expressed NbEILP in N. benthamiana plants, but the expression of full-length NbEILP-GFP was not detected in plants even with 10-fold protein loaded (Figure 5A). However, the accumulation of BaMV was approximately 1.6fold that of the control (Figure 5B) even though NbEILP expression was under detectable limit on western blot analysis. The expression of NbEILP/ $\triangle$ LRR-GFP could also enhance the accumulation of BaMV approximately 1.7-fold (Figure 5B). Hence, the LRR (790 amino acids), the major portion of NbEILP
(Figure 1), is not the critical determinant assisting BaMV movement.

\section{ER Membrane-Association Is Required for NbEILP Assisting BaMV Movement}

To determine which domain in NbEILP is involved in BaMV movement, we constructed mutants based on NbEILP/ $\triangle$ LRRGFP. The three deletion mutants involved removal of the 

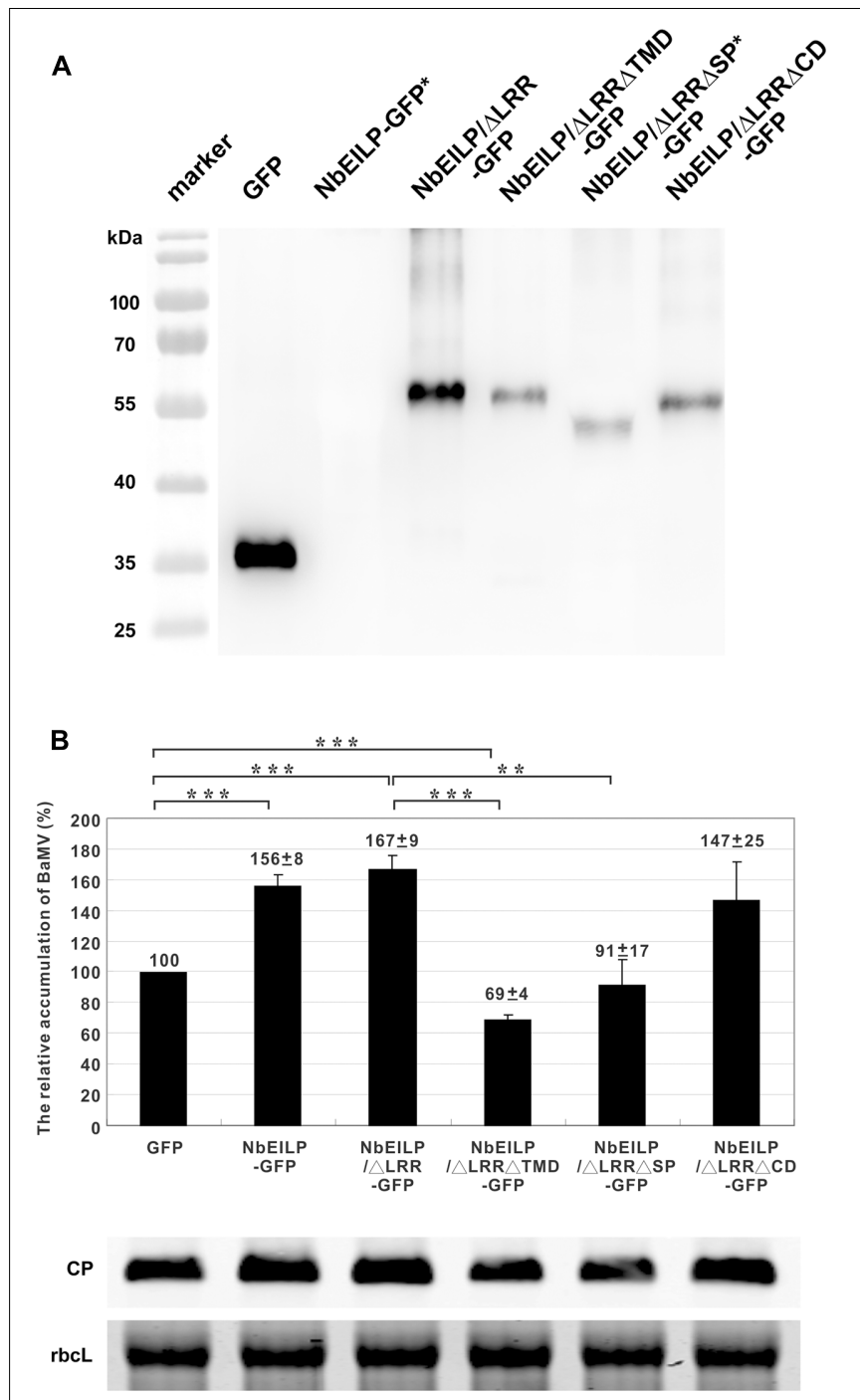

FIGURE 5 | Relative accumulation of BaMV CP in NbEILP- and derivative-expressed $N$. benthamiana plants. (A) GFP (pBI-mGFP1 vector only) and all NbEILP derivatives were co-infiltrated with p19 silencing suppressor in a 1:1 ratio. After 2 days, total protein was collected and extracted from $100 \mathrm{mg}$ of each infiltrated leaf and detected by western blot analysis. NbEILP-GFP and NbEILP/ $\Delta$ LRR $\Delta$ SP-GFP indicated as * were 10-fold loaded as compared with other samples. (B) Western blot analysis of the relative accumulation of $\mathrm{BaMV} \mathrm{CP}$ at $4 \mathrm{dpi}$ on $N$. benthamiana leaves with transient expression of GFP, NbEILP-GFP, NbEILP/ $\triangle$ LRR-GFP, NbEILP/ $\Delta$ LRR $\Delta$ TMD-GFP, NbEILP/ $\Delta$ LRR $\Delta$ SP-GFP, and $\mathrm{NbEILP} / \Delta$ LRR $\Delta \mathrm{CD}$-GFP by agro-infiltration. The data from western blot analysis were normalized to that of the large subunit of RuBisCO (rbcL) as the loading control stained with Coomassie blue. The numbers above bars are the mean and standard error of at least three independent experiments. Asterisks indicate statistically significant differences compared with the group indicated $\left.{ }^{* *} P<0.01,{ }^{* * *} p<0.001\right)$ by Student's $t$-test.

transmembrane domain (NbEILP/ $\Delta$ LRR $\Delta$ TMD-GFP), cytoplasmic domain (NbEILP/ $\Delta$ LRR $\Delta$ CD-GFP), and signal peptide (NbEILP/ $\triangle$ LRR $\Delta$ SP-GFP). After proteins were transiently expressed in N. benthamiana plants, total protein extracted from leaves was probed with anti-GFP antibody. The expression of
NbEILP/ $\triangle$ LRR $\triangle$ SP-GFP was limited and could be detected as compared with other proteins when 10 -fold more protein was loaded (Figure 5A).

Bamboo mosaic virus accumulation in the presence of NbEILP/ $\Delta$ LRR $\Delta$ TMD-GFP, NbEILP/ $\Delta$ LRR $\Delta$ SP-GFP, and $\mathrm{NbEILP} / \triangle \mathrm{LRR} \Delta \mathrm{CD}$-GFP was 69,91 , and $147 \%$, respectively, that of the control (Figure 5B). These results suggest that the transmembrane domain is the most critical region involved on BaMV accumulation. Mutant NbEILP/ $\triangle$ LRR $\Delta$ TMDGFP retaining the signal peptide but no transmembrane domain presumably could pass through the ER membrane into the lumen. With this process, NbEILP/ $\triangle$ LRR $\Delta$ TMD-GFP has a dominant-negative effect on BaMV accumulation (reduced to 69\% compared to the control). The signal peptide is also critical in that it directs NbEILP targeting to the ER membrane. As compared with NbEILP/ALRRGFP, with NbEILP/ $\Delta$ LRR $\Delta$ SP-GFP the accumulation of $\mathrm{BaMV} \mathrm{CP}$ in leaves was significantly reduced from 167 to $91 \%$ (Figure 5B), with no significant difference from that of the control GFP alone. Thus, NbEILP/ $\Delta$ LRR $\Delta$ SPGFP with removal of the signal peptide perhaps could not target the ER failing to assist BaMV movement. The cytoplasmic domain is irrelevant for BaMV accumulation because NbEILP/ $\triangle$ LRR $\Delta$ CD-GFP containing the signal peptide and transmembrane domain could still help with BaMV movement.

These results indicated that the variants of EILP proteins that are associated with the ER membrane upon expression by these constructs, such as NbEILP, NbEILP/ $\triangle$ LRRGFP, and NbEILP/ $\triangle$ LRR $\triangle$ CD-GFP are involved in BaMV accumulation. Confocal images of NbEILP/DLRR-GFP and $\mathrm{NbEILP/} \triangle \mathrm{LRR} \triangle \mathrm{CD}$-GFP confirmed this suggestion (Figure 4). Mutant NbEILP/ $\Delta$ LRR $\Delta$ SP-GFP without the signal peptide did not co-localize with the ER marker (Figure 4) and failed to assist in BaMV movement. However, NbEILP/DLRR $\triangle T M D-G F P$ co-localized with the ER but somehow had weaker signals than the constructs containing the transmembrane domain. The mutant NbEILP/ $\triangle$ LRR $\Delta$ TMD-GFP, containing the signal peptide but not the transmembrane domain, could be directed to enter the ER lumen.

\section{$\mathrm{NbEILP/} \Delta$ LRR-GFP and $\mathrm{NbEILP/} \Delta$ LRR $\Delta$ CD-GFP Are Membrane-Associated}

To validate the confocal microscopy findings, we fractionated the total protein extracted from BaMV-infiltrated leaves. NbEILP/ $\triangle$ LRR-GFP and NbEILP/ $\triangle$ LRR $\Delta$ CD-GFP were membrane-associated, whereas NbEILP/ $\triangle$ LRR $\Delta$ TMDGFP, retaining the signal peptide but not transmembrane domain, was mostly distributed to the soluble fraction (Figure 6).

Results from localization and BaMV accumulation experiments suggest that NbEILP and its derivatives localizing at the ER membrane could enhance BaMV accumulation. The results also imply that NbEILP localizing at the ER membrane plays a critical role in assisting BaMV movement. 


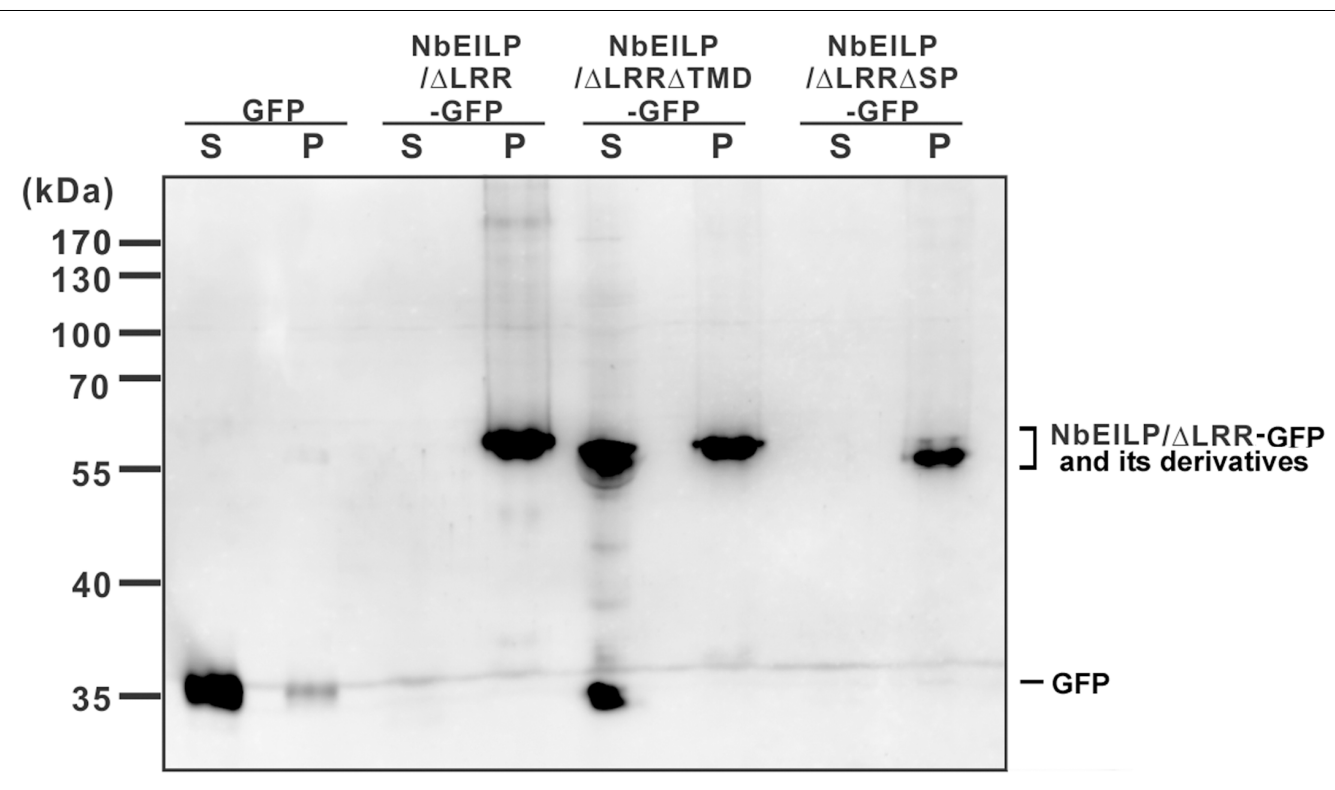

FIGURE 6 | Western blot analysis of transiently expressed proteins. Total protein was extracted from $N$. benthamiana plants with transient expression of GFP or $\mathrm{NbEILP} / \Delta$ LRR-GFP and its derivatives. The extracted proteins were fractionated into soluble $(\mathrm{S})$ and membrane-associated $(\mathrm{P})$ fractions, and separated on a $12 \%$ SDS-polyacrylamide gel for western blot analysis.

\section{DISCUSSION}

In this study, we cloned a gene upregulated after BaMV infection in $N$. benthamiana and determined how it is involved in virus accumulation. The full-length cDNA of this gene is approximately $3.2 \mathrm{~kb}$. The sequence for the polypeptide (NbEILP) encoded from this gene is similar to that of $C f$ $2 / C f-5$ genes in tomato, involved in resistance to strains of C. fulvum (Dixon et al., 1996), and the EILP in tobacco induced by treatment with salicylic acid (Takemoto et al., 2000). NbEILP has 32 LRRs, a transmembrane domain, and a short cytoplasmic domain. The LRR-containing domains are present in more than 60,000 proteins that are widespread in viruses, bacteria, archaea, and eukaryotes (Kobe and Kajava, 2001; Bella et al., 2008). All of these proteins have 20 to 30 residues in length in the conserved region LxxLxLxxNxL (L: Leu, Ile, Val, or Phe; N: Asn, Thr, Ser, or Cys; and $\mathrm{x}$ is any amino acid), which forms a highly conserved repeated $\beta$-strand/ $\beta$-turn structural motif in LRR proteins (Kobe and Deisenhofer, 1994). LRR domains are known as sites of protein-protein interaction, peptide-ligand binding, and protein-carbohydrate interaction that play a significant role in plant pathogen resistance (Jones and Jones, 1997; Kajava, 1998).

Although NbEILP shows sequence similarity to the resistance gene, it is specifically involved in BaMV movement. We did not observe any effect on the accumulation of PVX and CMV in NbEILP-knockdown plants (Supplementary Figure S4). Because NbEILP is a large protein (969 amino acids), transient expression of this protein in planta is difficult (Figure 5A). However, even with limited expression (undetectable on western blot analysis), the protein still could assist with BaMV accumulation (Figure 5B). The expression of NbEILP/ $\triangle$ LRR-GFP, with removal of LRR, could still retain the ability to assist BaMV movement. The LRR domain in NbEILP may not play an essential role in BaMV movement. However, the expression level of NbEILP is at least 10 -fold lower than that of NbEILP/ $\triangle L R R$; they can assist BaMV accumulation to a similar level (Figure 5). Therefore, we still could not rule out the possibility of the involvement of LRR in BaMV movement.

The results with the NbEILP derivatives indicated that only the constructs targeting the ER and retained on the membrane were involved in BaMV movement. The results imply that NbEILP could interact with the viral-encoded movement complex or gather the host-encoded factors that are crucial for viral movement. Therefore, NbEILP/ $\triangle$ LRR $\Delta$ TMD-GFP localized in the lumen of the ER (most likely), revealed to have a dominantnegative effect on BaMV accumulation (Figure 5B), could result from the viral movement complex, or the host factor crucial for the movement was trapped in the lumen.

For successful and efficient movement of a viral pathogen, different host factors were used to target the viral RNA replication particles and/or TGB proteins (in potexviruses) to the plasmodesmata via the endomembrane secretory pathway (most likely the ER and post-ER secretory pathway) (Ju et al., 2005; Tseng et al., 2009; Yoshimoto et al., 2010; Tilsner et al., 2012). A common strategy used by most of the positive-sense singlestranded RNA virus is to use the endomembrane systems for viral RNA replication (Pena and Heinlein, 2012; Tilsner et al., 2012). The secretory pathway is also commonly used for the newly synthesized progeny RNAs moving from the replication site to neighboring cells. TGBp1 of BaMV interacts with the viral RNA (Wung et al., 1999; Liou et al., 2000; Lin et al., 2004). TGBp2 and TGBp3 of BaMV are the ER-associated transmembrane proteins (Hsu et al., 2008; Tseng et al., 2009; Chou et al., 2013). As a native 
pathway of NbEILP for sensing the elicitors from pathogens, NbEILP is synthesized and retained on the ER membrane and is possibly secreted to the plasma membrane as vesicle trafficking. The movement complex containing TGBp1, vRNA, replicase, CP, TGBp2, and TGBp3 of BaMV (Chou et al., 2013; Huang et al., 2017) might take advantage of the secretory path of NbEILP to reach the plasmodesmata for cell-to-cell movement. Therefore, the possible role of NbEILP in BaMV movement could be gathering these viral- or host-encoded movement-associated proteins together. Here we identified a host protein NbEILP from $N$. benthamiana that is involved in BaMV cell-to-cell movement.

\section{AUTHOR CONTRIBUTIONS}

I-HC and C-HsT designed the research, analyzed the data and wrote the manuscript. Y-PH, C-HTse, J-TN, and C-HTsa performed the research. Y-HH and C-HsT participated in data analysis and discussion.

\section{REFERENCES}

Ahlquist, P., Noueiry, A. O., Lee, W. M., Kushner, D. B., and Dye, B. T. (2003). Host factors in positive-strand RNA virus genome replication. J. Virol. 77, 8181-8186. doi: 10.1128/JVI.77.15.8181-8186.2003

Bella, J., Hindle, K. L., Mcewan, P. A., and Lovell, S. C. (2008). The leucine-rich repeat structure. Cell Mol. Life. Sci. 65, 2307-2333. doi: 10.1007/s00018-0088019-0

Chen, I. H., Chou, W. J., Lee, P. Y., Hsu, Y. H., and Tsai, C. H. (2005). The AAUAAA motif of Bamboo mosaic virus RNA is involved in minus-strand RNA synthesis and plus-strand RNA polyadenylation. J. Virol. 79, 14555-14561. doi: 10.1128/JVI.79.23.14555-14561.2005

Chen, I. H., Huang, Y. W., and Tsai, C. H. (2017). The functional roles of the cisacting elements in Bamboo mosaic virus RNA genome. Front. Microbiol. 8:645. doi: 10.3389/fmicb.2017.00645

Cheng, S. F., Huang, Y. P., Wu, Z. R., Hu, C. C., Hsu, Y. H., and Tsai, C. H. (2010). Identification of differentially expressed genes induced by Bamboo mosaic virus infection in Nicotiana benthamiana by cDNA-amplified fragment length polymorphism. BMC Plant Biol. 10:286. doi: 10.1186/1471-2229-10-286

Chou, Y. L., Hung, Y. J., Tseng, Y. H., Hsu, H. T., Yang, J. Y., Wung, C. H., et al. (2013). The stable association of virion with the triple-gene-block protein 3based complex of Bamboo mosaic virus. PLOS Pathog. 9:e1003405. doi: 10.1371/ journal.ppat.1003405

Dangl, J. L., and Jones, J. D. (2001). Plant pathogens and integrated defence responses to infection. Nature 411, 826-833. doi: 10.1038/35081161

de Wit, P. J., and Joosten, M. H. (1999). Avirulence and resistance genes in the Cladosporium fulvum-tomato interaction. Curr. Opin. Microbiol. 2, 368-373. doi: 10.1016/S1369-5274(99)80065-4

DiMaio, F., Chen, C. C., Yu, X., Frenz, B., Hsu, Y. H., Lin, N. S., et al. (2015). The molecular basis for flexibility in the flexible filamentous plant viruses. Nat. Struct. Mol. Biol. 22, 642-644. doi: 10.1038/nsmb.3054

Dixon, M. S., Golstein, C., Thomas, C. M., Van Der Biezen, E. A., and Jones, J. D. (2000). Genetic complexity of pathogen perception by plants: the example of Rcr3, a tomato gene required specifically by Cf-2. Proc. Natl. Acad. Sci. U.S.A. 97, 8807-8814. doi: 10.1073/pnas.97.16.8807

Dixon, M. S., Jones, D. A., Keddie, J. S., Thomas, C. M., Harrison, K., and Jones, J. D. (1996). The tomato Cf-2 disease resistance locus comprises two functional genes encoding leucine-rich repeat proteins. Cell 84, 451-459. doi: 10.1016/ S0092-8674(00)81290-8

Ho, T. L., Lee, H. C., Chou, Y. L., Tseng, Y. H., Huang, W. C., Wung, C. H., et al. (2017). The cysteine residues at the C-terminal tail of Bamboo mosaic virus triple gene block protein 2 are critical for efficient plasmodesmata localization of protein 1 in the same block. Virology 501, 47-53. doi: 10.1016/j.virol.2016. 11.005

\section{FUNDING}

This study was financially supported by the Ministry of Science and Technology of Taiwan (MOST 105-2311-B-005-002).

\section{ACKNOWLEDGMENT}

We appreciate the Bioimage Core Laboratory of the Graduate Institute of Biotechnology at National Chung Hsing University for use of the facility and assistance.

\section{SUPPLEMENTARY MATERIAL}

The Supplementary Material for this article can be found online at: https://www.frontiersin.org/articles/10.3389/fpls.2017.01736/ full\#supplementary-material

Howard, A. R., Heppler, M. L., Ju, H. J., Krishnamurthy, K., Payton, M. E., and Verchot-Lubicz, J. (2004). Potato virus X TGBp1 induces plasmodesmata gating and moves between cells in several host species whereas CP moves only in N. benthamiana leaves. Virology 328, 185-197. doi: 10.1016/j.virol.2004.06.039

Hsu, H. T., Chou, Y. L., Tseng, Y. H., Lin, Y. H., Lin, T. M., Lin, N. S., et al. (2008). Topological properties of the triple gene block protein 2 of Bamboo mosaic virus. Virology 379, 1-9. doi: 10.1016/j.virol.2008.06.019

Huang, C. Y., and Tsai, C. H. (1998). Evolution of Bamboo mosaic virus in a nonsystemic host results in mutations in the helicase-like domain that cause reduced RNA accumulation. Virus Res. 58, 127-136. doi: 10.1016/S01681702(98)00109-9

Huang, Y. L., Hsu, Y. H., Han, Y. T., and Meng, M. (2005). mRNA guanylation catalyzed by the S-adenosylmethionine-dependent guanylyltransferase of Bamboo mosaic virus. J. Biol. Chem. 280, 13153-13162. doi: 10.1074/jbc. M412619200

Huang, Y. P., Chen, I. H., and Tsai, C. H. (2017). Host factors in the infection cycle of Bamboo mosaic virus. Front. Microbiol. 8:437. doi: 10.3389/fmicb.2017.00437

Hyodo, K., and Okuno, T. (2016). Pathogenesis mediated by proviral host factors involved in translation and replication of plant positive-strand RNA viruses. Curr. Opin. Virol. 17, 11-18. doi: 10.1016/j.coviro.2015.11.004

Jones, D. A., and Jones, J. D. G. (1997). The role of leucine-rich repeat proteins in plant defences. Adv. Bot. Res. 24, 89-167. doi: 10.1016/S0065-2296(08)60072-5

Joosten, M., and de Wit, P. (1999). The tomato-Cladosporium fulvum interaction: a versatile experimental system to study plant-pathogen interactions. Annu. Rev. Phytopathol. 37, 335-367. doi: 10.1146/annurev.phyto.37.1.335

Ju, H. J., Samuels, T. D., Wang, Y. S., Blancaflor, E., Payton, M., Mitra, R., et al. (2005). The Potato virus X TGBp2 movement protein associates with endoplasmic reticulum-derived vesicles during virus infection. Plant Physiol. 138, 1877-1895. doi: 10.1104/pp.105.066019

Kajava, A. V. (1998). Structural diversity of leucine-rich repeat proteins. J. Mol. Biol. 277, 519-527. doi: 10.1006/jmbi.1998.1643

Kobe, B., and Deisenhofer, J. (1994). The leucine-rich repeat: a versatile binding motif. Trends Biochem. Sci. 19, 415-421. doi: 10.1016/0968-0004(94)90090-6

Kobe, B., and Kajava, A. V. (2001). The leucine-rich repeat as a protein recognition motif. Curr. Opin. Struct. Biol 11, 725-732. doi: 10.1016/S0959-440X(01) 00266-4

Krishnamurthy, K., Heppler, M., Mitra, R., Blancaflor, E., Payton, M., Nelson, R. S., et al. (2003). The Potato virus X TGBp3 protein associates with the ER network for virus cell-to-cell movement. Virology 309, 135-151. doi: 10.1016/S00426822(02)00102-2

Laliberte, J. F., Beauchemin, C., and Boutet, N. (2007). Visualization of the interaction between the precursors of $\mathrm{VPg}$, the viral protein linked to the genome of Turnip mosaic virus, and the translation eukaryotic initiation factor iso 4E in planta. J. Virol. 81, 775-782. doi: 10.1128/JVI.01277-06 
Lan, P., Yeh, W. B., Tsai, C. W., and Lin, N. S. (2010). A unique glycine-rich motif at the N-terminal region of Bamboo mosaic virus coat protein is required for symptom expression. Mol. Plant Microbe Interact. 23, 903-914. doi: 10.1094/ MPMI-23-7-0903

Lee, C. C., Ho, Y. N., Hu, R. H., Yen, Y. T., Wang, Z. C., Lee, Y. C., et al. (2011). The interaction between Bamboo mosaic virus replication protein and coat protein is critical for virus movement in plant hosts. J. Virol. 85, 12022-12031. doi: 10.1128/JVI.05595-11

Li, Y. I., Chen, Y. J., Hsu, Y. H., and Meng, M. (2001a). Characterization of the AdoMet-dependent guanylyltransferase activity that is associated with the $\mathrm{N}$ terminus of Bamboo mosaic virus replicase. J. Virol. 75, 782-788.

Li, Y. I., Cheng, Y. M., Huang, Y. L., Tsai, C. H., Hsu, Y. H., and Meng, M. (1998). Identification and characterization of the Escherichia coli-expressed RNA-dependent RNA polymerase of Bamboo mosaic virus. J. Virol. 72, 10093-10099.

Li, Y. I., Shih, T. W., Hsu, Y. H., Han, Y. T., Huang, Y. L., and Meng, M. (2001b). The helicase-like domain of plant potexvirus replicase participates in formation of RNA $5^{\prime}$ cap structure by exhibiting RNA 5' -triphosphatase activity. J. Virol. 75, 12114-12120.

Lin, M. K., Chang, B. Y., Liao, J. T., Lin, N. S., and Hsu, Y. H. (2004). Arg-16 and Arg-21 in the N-terminal region of the triple-gene-block protein 1 of Bamboo mosaic virus are essential for virus movement. J. Gen. Virol. 85, 251-259. doi: 10.1099/vir.0.19442-0

Lin, M. K., Hu, C. C., Lin, N. S., Chang, B. Y., and Hsu, Y. H. (2006). Movement of potexviruses requires species-specific interactions among the cognate triple gene block proteins, as revealed by a trans-complementation assay based on the Bamboo mosaic virus satellite RNA-mediated expression system. J. Gen. Virol. 87, 1357-1367. doi: 10.1099/vir.0.81625-0

Lin, M. T., Kitajima, W. E., Cupertino, P. F., and Costa, C. L. (1977). Partial purification and some properties of Bamboo mosaic virus. Phytopath 67, 1439-1443. doi: 10.1094/Phyto-67-1439

Lin, N. S., Lin, B. Y., Lo, N. W., Hu, C. C., Chow, T. Y., and Hsu, Y. H. (1994). Nucleotide sequence of the genomic RNA of Bamboo mosaic potexvirus. J. Gen. Virol. 75, 2513-2518. doi: 10.1099/0022-1317-75-9-2513

Liou, D. Y., Hsu, Y. H., Wung, C. H., Wang, W. H., Lin, N. S., and Chang, B. Y. (2000). Functional analyses and identification of two arginine residues essential to the ATP-utilizing activity of the triple gene block protein 1 of Bamboo mosaic potexvirus. Virology 277, 336-344. doi: 10.1006/viro.2000.0610

Meng, M., and Lee, C. C. (2017). Function and structural organization of the replication protein of Bamboo mosaic virus. Front. Microbiol. 8:522. doi: $10.3389 /$ fmicb. 2017.00522

Mitra, R., Krishnamurthy, K., Blancaflor, E., Payton, M., Nelson, R. S., and VerchotLubicz, J. (2003). The Potato virus X TGBp2 protein association with the endoplasmic reticulum plays a role in but is not sufficient for viral cell-to-cell movement. Virology 312, 35-48. doi: 10.1016/S0042-6822(03)00180-6

Nagy, P. D. (2016). Tombusvirus-host interactions: co-opted evolutionarily conserved host factors take center court. Annu. Rev. Virol. 3, 491-515. doi: 10.1146/annurev-virology-110615-042312

Nelson, B. K., Cai, X., and Nebenfuhr, A. (2007). A multicolored set of in vivo organelle markers for co-localization studies in Arabidopsis and other plants. Plant J. 51, 1126-1136. doi: 10.1111/j.1365-313X.2007.03212.x

Park, M. R., Jeong, R. D., and Kim, K. H. (2014). Understanding the intracellular trafficking and intercellular transport of potexviruses in their host plants. Front. Plant Sci. 5:60. doi: 10.3389/fpls.2014.00060
Pena, E. J., and Heinlein, M. (2012). RNA transport during TMV cell-to-cell movement. Front. Plant Sci. 3:193. doi: 10.3389/fpls.2012.00193

Perbal, M. C., Thomas, C. L., and Maule, A. J. (1993). Cauliflower mosaic virus gene I product (P1) forms tubular structures which extend from the surface of infected protoplasts. Virology 195, 281-285. doi: 10.1006/viro.1993.1375

Ruiz, M. T., Voinnet, O., and Baulcombe, D. C. (1998). Initiation and maintenance of virus-induced gene silencing. Plant Cell 10, 937-946. doi: 10.1105/tpc.10. 6.937

Ryabov, E. V., Robinson, D. J., and Taliansky, M. E. (1999). A plant virus-encoded protein facilitates long-distance movement of heterologous viral RNA. Proc. Natl. Acad. Sci. U.S.A. 96, 1212-1217. doi: 10.1073/pnas.96.4.1212

Shaner, N. C., Campbell, R. E., Steinbach, P. A., Giepmans, B. N., Palmer, A. E., and Tsien, R. Y. (2004). Improved monomeric red, orange and yellow fluorescent proteins derived from Discosoma sp. red fluorescent protein. Nat. Biotechnol. 22, 1567-1572. doi: 10.1038/nbt1037

Takemoto, D., Hayashi, M., Doke, N., Mishimura, M., and Kawakita, K. (2000). Isolation of the gene for EILP, an elicitor-inducible LRR receptor-like protein, from tobacco by differential display. Plant Cell Physiol. 41, 458-464. doi: $10.1093 / \mathrm{pcp} / 41.4 .458$

Tilsner, J., Linnik, O., Wright, K. M., Bell, K., Roberts, A. G., Lacomme, C., et al. (2012). The TGB1 movement protein of Potato virus $X$ reorganizes actin and endomembranes into the X-body, a viral replication factory. Plant Physiol. 158, 1359-1370. doi: 10.1104/pp.111.189605

Tsai, C.-H., Cheng, C.-P., Peng, C.-W., Lin, B.-Y., Lin, N.-S., and Hsu, Y.-H. (1999). Sufficient length of a poly(A) tail for the formation of a potential pseudoknot is required for efficient replication of Bamboo mosaic potexvirus RNA. J. Virol. 73, 2703-2709.

Tsai, C. H., and Dreher, T. W. (1991). Turnip yellow mosaic virus RNAs with anticodon loop substitutions that result in decreased valylation fail to replicate efficiently. J. Virol. 65, 3060-3067.

Tseng, Y. H., Hsu, H. T., Chou, Y. L., Hu, C. C., Lin, N. S., Hsu, Y. H., et al. (2009). The two conserved cysteine residues of the triple gene block protein 2 are critical for both cell-to-cell and systemic movement of Bamboo mosaic virus. Mol. Plant Microbe Interact. 22, 1379-1388. doi: 10.1094/MPMI-22-11-1379

Wolf, S., Deom, C. M., Beachy, R. N., and Lucas, W. J. (1989). Movement protein of Tobacco mosaic virus modifies plasmodesmatal size exclusion limit. Science 246, 377-379. doi: 10.1126/science.246.4928.377

Wung, C. H., Hsu, Y. H., Liou, D. Y., Huang, W. C., Lin, N. S., and Chang, B. Y. (1999). Identification of the RNA-binding sites of the triple gene block protein 1 of Bamboo mosaic potexvirus. J. Gen. Virol. 80(Pt 5), 1119-1126. doi: 10.1099/0022-1317-80-5-1119

Yoshimoto, K., Takano, Y., and Sakai, Y. (2010). Autophagy in plants and phytopathogens. FEBS Lett. 584, 1350-1358. doi: 10.1016/j.febslet.2010.01.007

Conflict of Interest Statement: The authors declare that the research was conducted in the absence of any commercial or financial relationships that could be construed as a potential conflict of interest.

Copyright (c) 2017 Chen, Huang, Tseng, Ni, Tsai, Hsu and Tsai. This is an open-access article distributed under the terms of the Creative Commons Attribution License (CC BY). The use, distribution or reproduction in other forums is permitted, provided the original author(s) or licensor are credited and that the original publication in this journal is cited, in accordance with accepted academic practice. No use, distribution or reproduction is permitted which does not comply with these terms. 